Review

\title{
Performance Based Envelopes: A Theory of Spatialized Skins and the Emergence of the Integrated Design Professional
}

\section{Franca Trubiano}

Architecture Program, PennDesign, University of Pennsylvania, Philadelphia, PA 19106, USA;

E-Mail: trubiano@design.upenn.edu; Tel.: +1-215-746-6182; Fax: +1-215-573-2192

Received: 30 August 2013; in revised form: 26 September 2013 / Accepted: 30 September 2013 / Published: 11 October 2013

\begin{abstract}
Realigning the design of building envelopes within the measures of air, light and heat has rendered possible an inventive form of practice whose benefits are far in excess of the metrics of data and analysis. For many of its most advanced practitioners, the contemporary design of facades engages the true potential of "performance" when it deepens, broadens and complicates the theoretical dimension of this most liminal of surfaces. Of particular interest to this paper is a discussion of new theoretical paradigms associated with the design and operation of high performance envelopes of which four characteristics of this emergent sub-discipline are herein examined. To begin with, the way in which building envelopes are no longer separators, dividers and barriers between a building's interior and exterior conditions, but rather, "spatially" defined environments that fully engage the totality of a building's engineering systems, is discussed. Cantilevered Louvers, Double Skin Facades and Hybrid Conditioned Atria are representative of this new paradigm as is the use of Responsive Technologies to optimize their behaviors. Lastly, the paper examines the rise of the new integrated design building envelope professional called upon to deliver ever-better performing skins, whether in the guise of energy modeler, climate engineer or façade construction specialist. Hence, this paper develops a theoretical structure within which to describe, analyze and interpret the values made possible by this new and expanding field of performance based envelopes.
\end{abstract}

Keywords: building envelopes; energy; design theory; high performance; double skin 


\section{Introduction-Building Envelopes beyond the Measures of Data}

Much of the current discourse on energy efficiency and architectural design has coalesced around the subject of building skins. As highly technological devices, these works of architectural engineering are predicated on data based performance benchmarks, virtual simulations, and the laws of computational fluid dynamics. Increasingly, they are responsible for the conservation of energy, the maintenance of thermal comfort, and the optimization of daylight and fresh air distribution, and as such designed, constructed and operated to meet ever more prescriptive goals [1]. For many, refocusing the functionality of building envelopes on environmental metrics offers precisely the needed, vastly more objective terrain within which to evaluate their role as facades. For others, it only privileges the technological determinism of building physics at the exclusion of all other design considerations. What is clear, however, is that the vast quantity of information and data generated, simulated, collected, analyzed and associated with the energy loses and gains of building skins increases exponentially every year. A plethora of numbers and figures is now available to designers and engineers. For the large number of professionals whose clients continue to demand architectural envelopes constructed and operated to meet net zero goals, avoiding the use of data is not an option.

And yet, in and of itself, data is grossly insufficient for understanding the role skins play in the wider cultural context of buildings. Implicated in a number of direct and indirect functions, the design of building envelopes is often guided by constraints and intentions whose values are measured beyond the units of BTUs (British Thermal Units) and EUIs (Energy Use Intensity). Performance figures, for example, are wholly inadequate for communicating the vastly rhetorical function played by facades. As built emblems of a client's commitment to sustainability, building envelopes can be used to showcase the knowledge of, and disposition to, environmentally conscious architecture. Government bodies, as well as informed corporations, understand the increased public support and market value garnered by high performance buildings, such that during the past decade a number of high-profile projects have explicitly evidenced this form of messaging. London's City Hall, for example, built in 2002 by Foster and Associates was conceived, both formally and in its details, to represent the city's then commitment to sustainable building [2,3]. The San Francisco Federal Office Building, completed in 2007 by Thom Mayne of Morphosis, was commissioned to secure 50\% energy savings over the typical U.S. office building; a mandate dictated by the General Services Administration of the U.S. government [4,5]. And at the center of Stephen Holl's Linked Hybrid residential tower project, completed in 2009 in Beijing China, was the added financial value accrued by "green" labeling and LEED Certification. The project's enlightened use of geothermal sources for heating and cooling was indispensible to its marketing strategy and contributed to the financial success of its developers [6]. As these and other projects demonstrate, public and private commissions are often aided by the rhetorical power of environmental stewardship even if future value remains difficult to forecast and measure in the planning stages of projects (Figures 1 and 2).

Ensuring the cultural heritage of a place is equally important for the practice of architectural figuration. The appearance of cities and towns is, in many instances, an historical imperative legally registered in zoning codes with immediate consequences for the renovation and refurbishment of existing buildings. Much of the fabric built in Western Europe and North America, prior to and during the 20th century, will require substantial amounts of retrofitting as end-of-life approaches for millions 
of windows, heating, ventilating and air-conditioning systems. And while this represents an as yet untapped potential for high-performance skins, the introduction of new material technologies, such as plastics and composites, often gives rise to conflicting opinions when used in historically significant urban environments [7]. In the case that emergent non-traditional globalized technologies are promoted for meeting high performance goals, consideration is best given to the heritage value of vernacular building practices.

Figure 1. London City Hall-Foster and Associates (Courtesy Terri Boake, University of Waterloo).

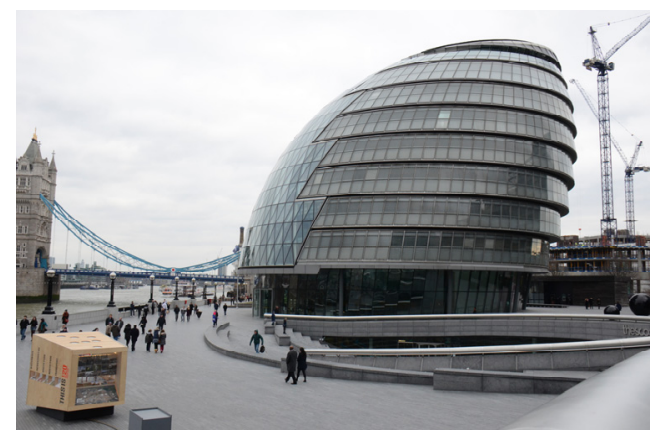

Figure 2. Linked Hybrid—Steven Holl (Courtesy Terri Boake, University of Waterloo).

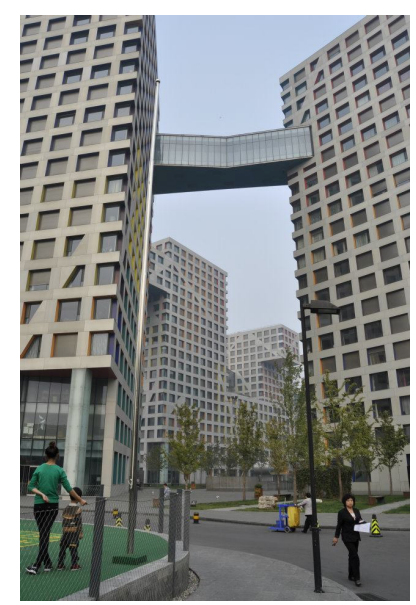

Equally important when addressing the merit of building envelopes is their ability to meet the cost targets of building owners. In addition to energy saved by initial load reduction, high performance envelops secure financial gains and higher returns on investment when they minimize operating expenditures. Increasingly these values are factored into a building's overall financial equation and in the best of circumstances used to counteract the escalation of future costs. With economic forecasts clearly indicating that operating and maintenance expenditures will soon exceed construction costs, building developers and tenants are returning in greater numbers to building physics and expert engineering to procure the most efficient building skins possible. In a highly competitive real estate market, the ability to advertise lower operating costs surely contributes to the business success of early adopters [8].

In summary, therefore, the design, construction, and operation of building envelopes is best served when rhetorical, political, cultural and financial factors are considered alongside the metrics of 
analysis. Surely, a far more comprehensive definition of building envelope performance is possible when qualitative values are assessed in equal measure to quantitative ones.

\section{Defining New Paradigms for Their Design and Operations}

Contemporary envelopes, when designed using performance based metrics attendant to air, light and heat give rise to an inventive form of practice, which albeit involves the processing of vast amounts of data, also registers benefits far in excess of said data [9-12]. In fact, engineering highly responsive facades secures a heightened definition of "performance" when engaging the more speculative dimension of building skins. When novel design ideas are captured and represented across this most liminal of surfaces, the every way in which we think about building envelopes is fundamentally challenged. What emerges is an alternative paradigm for a theory of building.

No longer are envelopes conceived as dematerialized barriers between a building's interior and exterior conditions, but rather as spatially determined environments fully engaged in the totality of a building's engineering systems. With the goal of significant reductions in energy use, design techniques, both old and new, are being developed and implemented to maximize environmental gains such as improved air and water quality, material reuse and recycling, resourceful site management, and reduced carbon emissions, amongst others. They also contribute much needed value to the figural language of architecture.

Four such techniques are discussed and illustrated in this paper of which the propensity to increase the "depth" of the envelope is common to all. Whether by the projection of exterior planes; the multiplication of material layers for moving and exchanging air, light, and heat at the exterior surface of the building; the introduction of program based architectural volumes that replace a building's mechanical systems; or the introduction of responsive electronics, the sum of these technological imperatives is the material, dimensional, tectonic, and digital "spatialization" of the skin. In deepening the section of the skin, each of these four techniques have reconfigured the performance mandate of building envelopes and in so doing have changed the very nature of how buildings appear.

Moreover, heightened interest in energy responsive facades and a true commitment to their benchmarking has given rise to a new building industry professional. At present, a cadre of designers and engineers, often in direct collaboration, are called upon to deliver practice-based skills for coordinating the science of building physics with the art of architecture. Energy auditors, modelers and simulators are amongst the professionals who contribute levels of specialized knowledge previously unavailable to design, while a new breed of designers now provide questions to the process of programmatic and formal importance. Only the most innovative of these consultants is capable of acting as climate engineer and integrated design expert offering a range of billable services rarely considered necessary prior to the 21 st century. The work of Transsolar, Atelier 10, Front Inc., ARUP Associates, Buro Happold, and Werner Sobek Engineers is exemplary in this regard and the subject of this paper (Figures 3 and 4).

Required, therefore, is a theoretical structure within which to describe, analyze and interpret the nascent values made possible by this quickly expanding field of high performance facades. Essential is an intellectual framework for evaluating its various tenets as well as for assessing its potential deficiencies. And to this end, the remainder of this paper is addressed. 
Figure 3. Water Cube Project in Beijing, China, ARUP Associates (Courtesy Terri Boake, University of Waterloo).
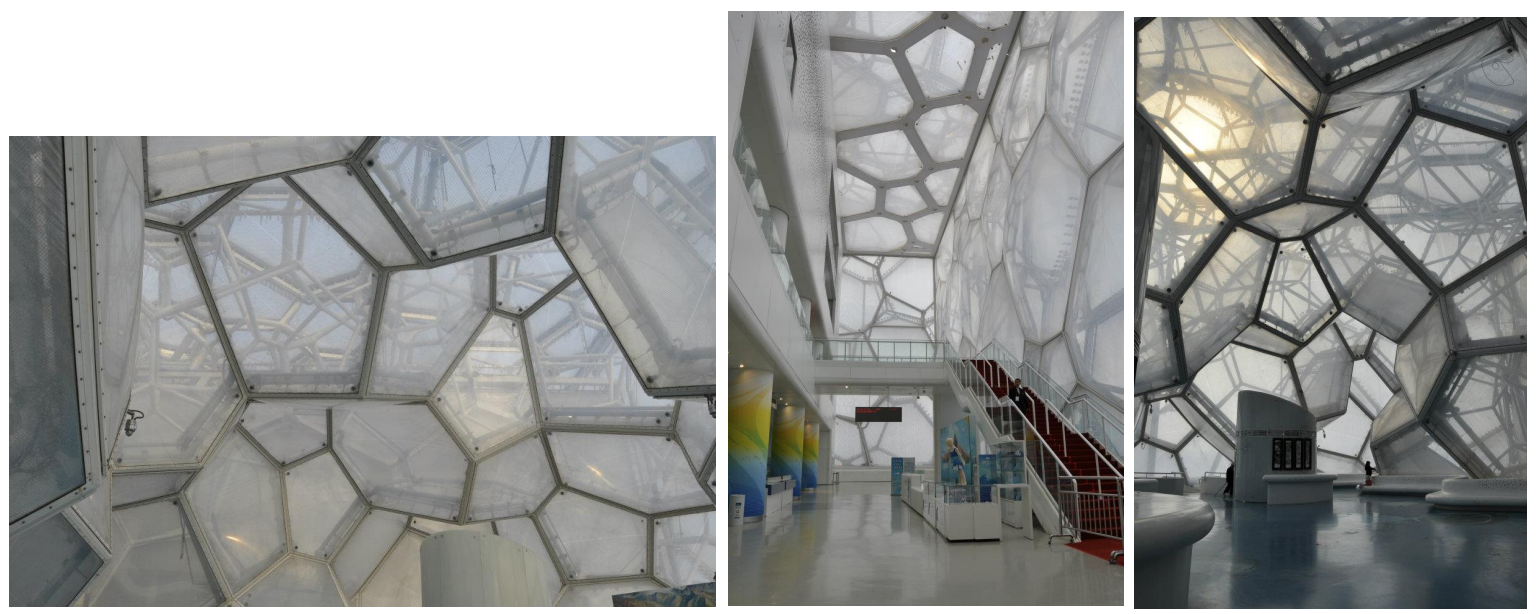

Figure 4. Lincoln Square Synagogue (Courtesy Front, NY).

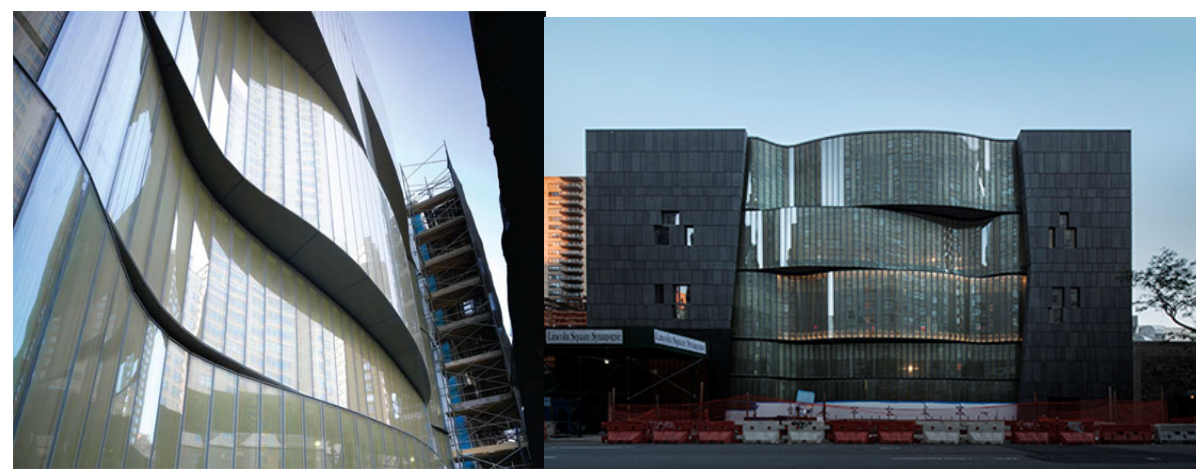

\section{Spatialized Skins-Engineering the Depth of Building Envelopes}

Building envelopes are, by definition, central to the thermal and environmental regulation of a building's interior. The materials with which they are built, as well as the number and placement of operable openings, contribute directly to their functionality. Even the most vernacular and traditional of structures were ecologically dependent on their envelopes for passive thermal regulation; masonry load bearing walls were suited for harvesting thermal gains in the colder wintry climates of western Europe, while wood frame, bamboo matting and palm fibers conducive to increased ventilation during the hot and humid summers of the tropics. In the best of circumstances, the envelope is always designed to operate sympathetically with the climate in which it is located, offering occupants a balanced thermal environment [13].

Since the mid 20th century however, the use of engineered mechanical systems has become near ubiquitous for maintaining the thermal comfort of buildings. In the United States, the installation of heating, ventilating and cooling equipment for new construction and renovations has become standard operating procedure. And precisely the pervasive adoption of these energy-consuming technologies, for mitigating even the lightest of loads, has had significant and unforeseen consequences. Not only has it drastically reduced the sustainability profile of most buildings, it has changed the way in which we "think" about architecture [14]. 
Reyner Banham was among the first in the mid 1960s to recognize the impact which energy would have on how buildings are designed and used. In Architecture of the Well Tempered Environment, he identified a number of representative 19th and 20th century buildings conceived and engineered using the "regenerative mode" of design which required the expenditure of "applied energy" [15-18]. Energy consuming technologies such as the Franklin stove, the Rumford fireplace, the Sirocco fan and the Willis Carrier air conditioner were each invented with a view to increasing the thermal comfort of environments. And in arguing that a work of architecture was more than the sum of its constructed parts, Banham introduced us to architects and patrons committed to the environmental expression of architectural space; citing the work of Frank Lloyd Wright and Le Corbusier, the industrial factories built by Olivetti in Argentina and the Queen Elizabeth Hall built on London's South Bank.

Banham did not however, acknowledge the long-term consequences this regenerative mode of design would have for fossil fuel consumption. In fact, so committed was he to the idea that designing with energy could give rise to a far different world, he believed the very essence of "home" could be altered by the shape defining capacity of energy. This was clearly notable in Banham's highly polemical article, "A Home is not a House" which promoted architectural skins as the thinnest of surfaces, dematerialized and highly transparent. Representing the one-person home as a capsule built of inflated polyethylene films, in this alternative narrative of "home" the house was effectively no more physical than a soap bubble [19]. Surely by today's standards Banham's utopia was paradoxical, unsustainable, and environmentally dangerous.

But this dream was not his alone. Heating, ventilating and air-conditioning engineers and suppliers shared in its diffusion, albeit in a far more pedestrian manner and for far more prosaic reasons. In the early days of access to infinite quantities of energy, when vast amounts of cooled and heated air were delivered at will to factories, warehouses, office buildings and retail malls, a significant disconnect arose in the design of buildings and their systems. Facades were engineered at cross-purposes to the optimal operation of lighting, heating, ventilating and cooling equipment. Even during the first OPEC energy crisis of 1973, architects and their clients increased the window to wall ratio for commercial multi-story buildings to nearly $100 \%$ in the belief that oversized building systems could easily mitigate any excess in solar heat engendered by these highly transparent façades. This modus operandi by North American architects and building system engineers was unwise and highly unsustainable.

In direct contrast, building envelope design of the 21 st century addresses precisely this incongruity in the industry. Seeking their mutual optimization, the performance of building envelopes is engineered in direct synchronization with the building's mechanical systems. Air-flow, heat transfer, and light transmission are studied, analyzed and simulated for their consequences to the building's skin as for their impacts on the vast network of equipment required in maintaining the thermal comfort of a building; their mutual interdependence now being the aim of the design process.

In this sense, the envelope acquires truly spatial characteristics. Contrary to its conceptualization at the end of the 19th century and its technological development during the mid 20th century, an entirely different paradigm exists at present for "thinking" the skin. No longer an "infill" to a frame-universal, highly interchangeable, suspended in a curtain wall and in surplus of the structure-contemporary building envelopes have complicated their portrayal as dematerialized membranes in search of maximum transparency. 
Recruited in actively improving a building's overall energy performance, contemporary high performance facades transcend the design tenets of their recent past by advancing the new paradigm of "spatialized" skins. They've transformed the very concept of building envelopes, from dematerialized curtain-walls to built essays in "spatialization". By layering, multiplying, and thickening their perceived and actual depth, building skins have acquired a measurable, occupiable and operable dimension. Using compound planes of membranes and films, these newly fashioned envelopes capture interstitial spaces of great import; for not only do they advance the energy performance of the building's they enclose, they also represent a new way of thinking about the envelope for those desirous of surface depth and substance.

\subsection{Projecting Solar Depth-Cantilevered Louvers}

Spatialized skins augment their sectional interface with the environment in one of four ways. Initially and most simply, the addition of active and/or passive elements outboard of the skin increases or decreases the amount of light and solar energy introduced within the building. Solar shades, awnings, light shelves, and retractable blinds facilitate light and heat control all the while animating the architectural figuration of the facade. Many a brise soleil, whether fixed or mechanically powered by actuators, is used to reduce solar heat gain while effectively singularizing a building's appearance. The early work of émigré architects Victor and Aldar Olgyay identified the currency with which these design features and figures had been deployed in early modern and mid century modern architecture [20,21]. Design With Climate: Bioclimatic Approach to Architectural Regionalism [20] and Solar Control and Shading Devices [21] were the first publications to offer practicing architects simple rules of thumb for designing their own devices and for recognizing the ecological and regional factors incumbent with solar design. At present, the most advanced digital software, including Maya, Rhino, Revit, Grasshopper, Ladybug, and MATLAB are used to model and analyze optimal responsive solutions for solving the riddle of surface shading. In a manner far more computationally sophisticated than that used by the Olgyays, designers are scripting a full range of spatial responses, including the use of genetic algorithms, in the quest for a universal and infinitely reconfigurable shading device $[22,23]$. Notwithstanding the vastly utopic trajectory of this current research, in all instances, it is the thickened material depth of the façade, by elements that project outboard of the thermal envelope that defines the most elemental of techniques for "spatialization" of skins.

It is a simple yet effective technique that has produced some of the most articulate building façades in recent years. One small-scaled project to have taken this idea to heart is the Lycée Albert Camus built in Fréjus, France, by architects Foster + Partners in 1993 [24]. Conceived as a fully integrated building, the high school minimizes the use of artificial systems to maximize the value and benefits of its location in the south of France. Amongst its inventions for the control of solar shading is the 5-m long south facing canopy that runs the length of the east/west axis of the school's all glass façade. The white anodized perforated metal canopy not only helps to ventilate the space in front of the glass but it also creates an external room of deepened shadows. The luminous character generated by this somewhat disproportionally wide overhang is both inviting and haunting. As a highly scripted exterior environment it offers thermal and solar respite, but it also proposes an atmosphere of deep mystery. It is neither an exterior or interior space, for captured under the building's signatory canopy is the 
physical embodiment of a liminal state of being; one, very much aligned with the practiced philosophy of the school's name sake (Figure 5).

Figure 5. Lycée Albert Camus, Foster + Partners, Reprinted with Permission from (C) Dennis Gilbert/VIEW.
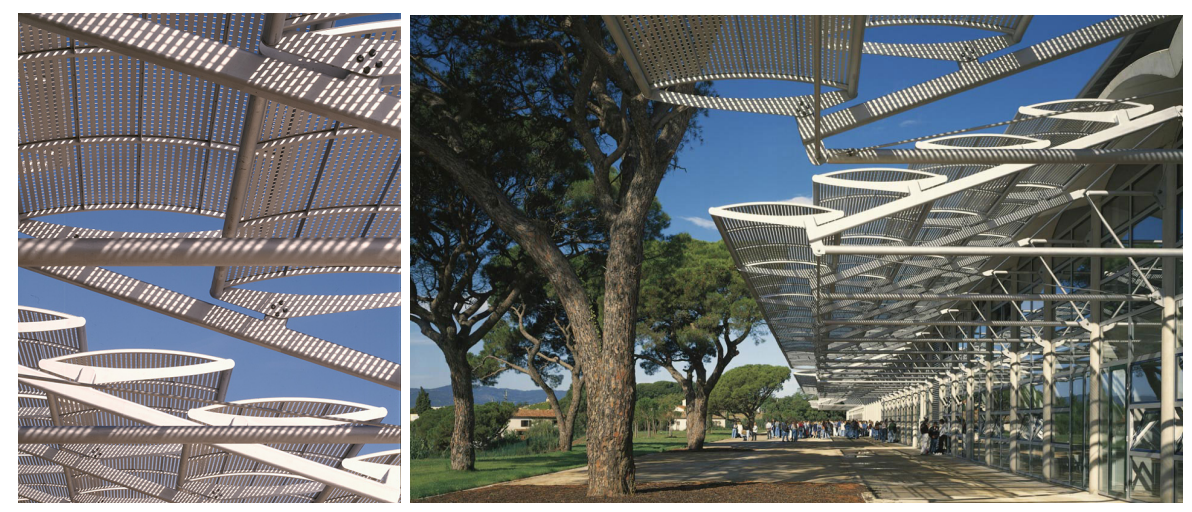

\subsection{Capturing the Flow of Air-Double Skin Facades}

Building envelopes further increase their perceptual and operational depth when more than one layer of glass, film or membrane is used to create interstitial spaces between inside and outside. It is this particular invention, in which space is bound between the layers of a double skin façade, that has captured the designer's imagination, like no other in recent history. Designed and engineered with the building's overall performance in mind, this interstitial cavity, as narrow as $15 \mathrm{~cm}$ or as wide as a meter, can function in a number of different ways to address all aspects of a building's environmental systems [25]. Typically, one or two air spaces are engineered to respond to the particular exigencies of daylight and thermal comfort. When sealed during the winter and oriented for maximum solar heat gain, the thermal energy collected in the cavity can be used to offset the temperature delta between inside and outside. When ventilated during cool spring, summer, and fall evenings, a significant drop in temperature can be registered on the cavity's inner skin contributing to energy free cooling. A double skin façade is equally functional for controlling daylight, with sensors and shading devices routinely installed in the cavity to regulate the transmission of luminance and the rejection of heat [10].

As built and operated in Europe, North America and Asia, this architectural contrivance has reanimated the theoretical register of building envelopes by overtly rejecting the modern narrative in which facades as read as essays in dematerialization. Moreover, "active" double skin facades challenge the very desirability of shallow building envelopes when the interstitial space they delimit is operationally connected to one or more of the building's systems. With the aim of reducing overall energy consumption, "active" double skin facades not only reduce load, they ventilate, increase daylight transmission, recover, transfer and evacuate heat, and generate power; doing so, in coordination with the building's heating, ventilation, and air-conditioning systems [12]. The full range of natural elements which interact with the envelope are either rejected, channeled, exhausted or recycled, between the first and second layers of glass, to produce fresh, heated, refrigerated or dehumidified air (Figures 6 and 7). 
Figure 6. Transsolar Double Skin Façade-Sparkasse Rosenheim, Reprinted with Permission from (C) Transsolar.

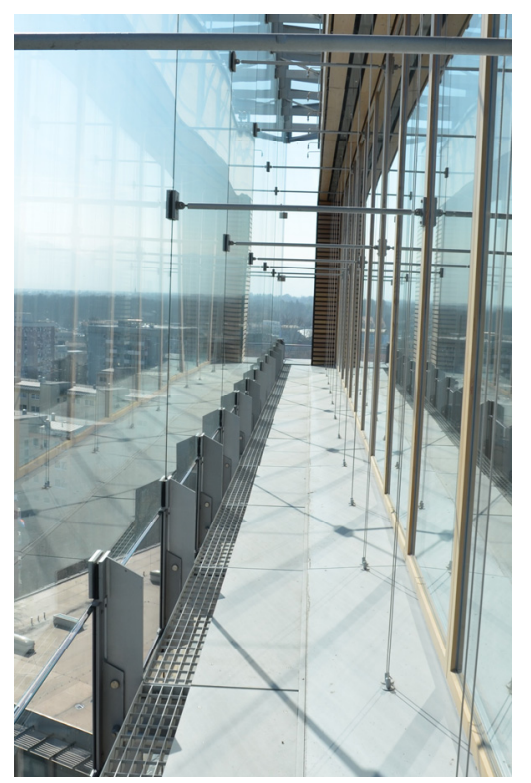

Figure 7. Transsolar Double Skin Façade - Loyola Info Commons, Reprinted with Permission from (C) 2008, James Steinkamp, Steinkamp Photography, (C) Solomon Cordwell Buenzs.

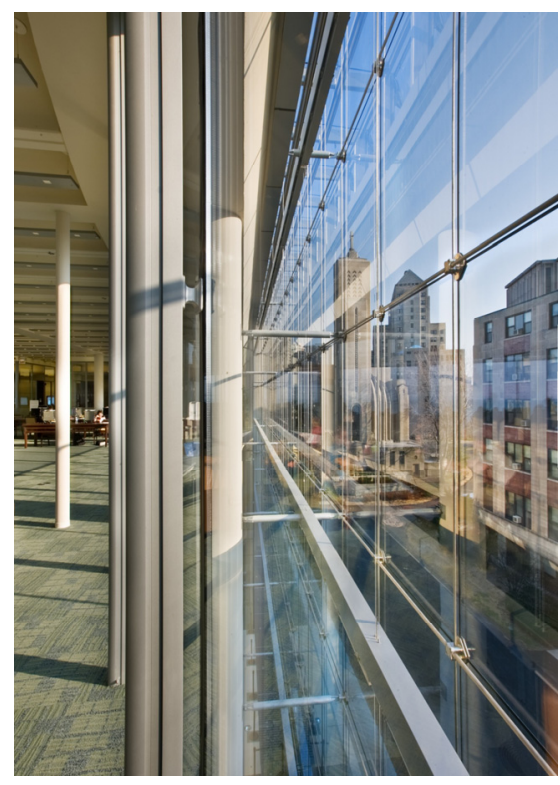

A number of functional categories exist. In some instances, the cavity is the full height of the building, whether connected or not to the building's systems; in others, the height of the cavity is limited to the height of one or two floors, whether or not, the cavity is connected to the building systems. The range of lighting, ventilation, heating and air conditioning requirements which double skin façade address is extensive; their integration the subject of invention and careful calibration as no two project requirements are the same [26].

Numerous double skin facades have been built during the past decade showcasing various permutations of said technologies and with an interest in evaluating their performance an associated field of academic research has resulted in order to monitor long term installed performance [27-29]. 
To date however, the value added performance of double skin facades remains inconclusive. While detractors have argued they only contribute to the excessive expenditure of materials at a cost that far exceeds any projected gains in operational energy; supporters continue to defend the validity of the science that subtends the practice. Post construction monitoring is now key for benchmarking the actual behavior of double skin facades against projected or simulated behaviors. For only in this way can the gap between virtual and in-situ performance be calibrated and necessary corrections and adjustments made to ensure proper operations. There is no more dynamic a set of parameters than the interdependent thermal, material, ventilation, and lighting responses found in a double skin façade.

Remarkably, its early origins date to the end of the 18th century, when the American born inventor and self-proclaimed natural philosopher, Sir Benjamin Thompson-known more commonly as Count Rumford (1753-1814), investigated the source of friction borne heat as well as the heat conductivity of various materials. When collecting insulation values for various materials, Rumford had made the crucial observation that air was an effective insulator. In response, he conceived the first double pane glazing unit having observed that air was "a perfect non-conductor of heat" when it occupied "the interstices of substances" [30]. During the 20th century, this early observation gave rise to the most simplest of architectural products, the "insulated glazing unit" (IGU) in which two sheets of glass are held apart for a maximum of 0.5 inches $(12.5 \mathrm{~mm})$ in order to increase the thermal resistance of a single pane of glass.

It also contributed to the shift in "thinking" that is now the domain of double skin façades, wholly conceived to maximize the saving of energy in the operation of a building. The introduction of high-performance facades targets the downsizing and, wherever possible, the complete elimination of mechanical systems, particularly the most inefficient combined heating and cooling air-based systems typically used in multistory commercial buildings in North America. Given the premise that significant load reductions are possible when the thermal capacity of double skin facades is actualized, an increased number of new buildings have, in fact, replaced air with water as the principal means of energy transfer. Smaller, more efficient, chilled beams are now used in lieu of miles of hidden sheet metal ducts concealed in suspended ceilings [31]. And far from being a minor substitution, this shift in water based energy transportation has significantly altered the sectional logic of buildings by re-claiming the overhead space traditionally reserved for mechanical systems for the benefit of an increased spatial profile. It has also exposed the underside of concrete slabs to the potential of gains in thermal mass.

Exemplary early double skin facades include the Hanover Trade Fair Headquarters by Thomas Herzog + Partner (1999) and the Kursaal Convention Center in San Sebastian by Rafael Moneo (1999) [32]. More recently, the Terrence Donnelly Center for Cellular + Bio-molecular Research at the University of Toronto, designed by architectsAlliance and Behnisch Architekten, illustrates the many advantages of using a meter wide south facing air space. Its exterior skin is single glazed and its interior double-glazed; the cavity fitted with solar shading devices and operable aluminum louvers accommodating various lighting configurations. Ventilated as required, the cavity's operations are fully connected to a Building Automation System for optimizing performance. The London City Hall, mentioned in the opening paragraphs of this paper, also sports a double skin facade on the southern perimeter of the building which can be naturally ventilated between floors and whose solar heat gain is significantly minimized by reduced amounts of clear glazing located on the inner skin of the assembly. 
The full merits of this technology however, transcend the measure of energy. Active double skin façades vastly expand the representational function of buildings by assuming an architectural role well beyond that of "infill to a frame". In structurally supporting the full depth of the expanded cavity, in facilitating the complex transfer of heated and unheated air, and in calibrating the transmission of abundant natural daylighting, this truly "spatialised" skin recalibrates our expectations for architectural figuration. Cavities as wide as a meter invite human habitation, which when designed to occur reveals to the street the building's inner workings. And when cavities are engineered to maximize the benefits of natural ventilation, they disclose the variability of human comfort levels within the patterns of operable windows registered on the façade; whether the windows are controlled by building users or by a highly coordinated Building Automation System. In both instances, by bringing to the surface human activities and technologies otherwise well hidden in the core of most buildings, active double skin facades render visible and explicit that which has traditionally been banished from view and conversation.

And yet, the orchestration of energy efficient building envelopes can also occur amidst a certain degree of opacity. Precisely in the doubling of material layers and in the widening of the space between interior and exterior skins, activities traditionally programmed immediately adjacent to the glass skin are now positioned well inboard of public viewing. For many a corporate client this is a welcome change that affords employees an increased level of privacy. Double skin façades can increase levels of transparency so sought after by contemporary society, but they can also expand the palette of spatial invention by delaying, displacing and distancing the place of expected representations.

\subsection{Occupying the Envelope-Hybrid Conditioned Atria}

Building envelopes acquire a truly spatialized character when designed to contain a physically occupiable space. More than mere skin, these envelopes house an architectural environment with functional and programmatic requirements. Atria of various kinds are used in this manner when one or more of their edges form part of the building's envelope and the volume they define is involved in engineering the building's interior climate. By pre-heating, pre-cooling, humidifying or dehumidifying outside air destined for other parts of the building, these highly "spatialised" skins are large scale environments that directly influence the building's overall systems logic. When carefully engineered, they too can replace more highly consumptive technologies liberating large areas of the building, otherwise used for concealing undesirable equipment, for more socially relevant programming.

As in the case of double skin façades, so too with the introduction of atria whose volumes are engineered to augment energy performance, overall project value is enhanced in ways difficult to measure using only data and BTUs. These highly evocative multi-story, flexible, and versatile environments not only contribute to increased human interaction, but expand the reaches of design innovation through architectural programming. Typically, the location of public forms of circulation-including interoffice stairs, ramps and balconies-these spaces foster increased interpersonal engagements that substantially contribute to the betterment of daily work rituals.

The Swiss Re Tower designed by Foster + Partners in London in 2004 is particularly noteworthy in this regard because it is a double skin atrium façade built within a diagrid structural skin. Working 
alongside Arup's structural engineers, Foster achieved an exceptional level of design optimization in a singular geometric figure, resolving the scale of the entire building, with that of its structure, and with that of its skin. The typical office plan is small enough to avoid interior columns as well as the need for significant amounts of artificial lighting. And it modulates overall performance by actively collecting weather data such as temperature, air velocity, and solar insolation. This data is used to configure the building's double skin façade, which runs the circumference of the plan and is more than a meter deep. While the exterior glazing is a single pane of glass, the inner insulated glazing unit (IGU) contains computer-automated blinds [33] (Figures 8 and 9).

Figure 8. Swiss Re Tower, London, England-Foster and Associates (Courtesy Terri Boake, University of Waterloo).

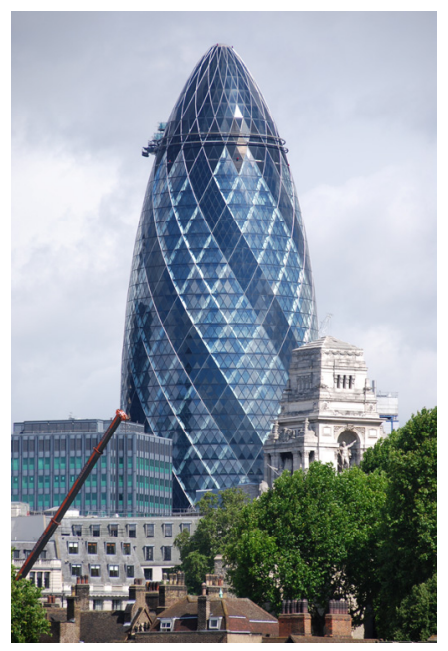

Figure 9. Swiss Re Tower-Interior Atrium (Courtesy Nigel Young/Foster + Partners).

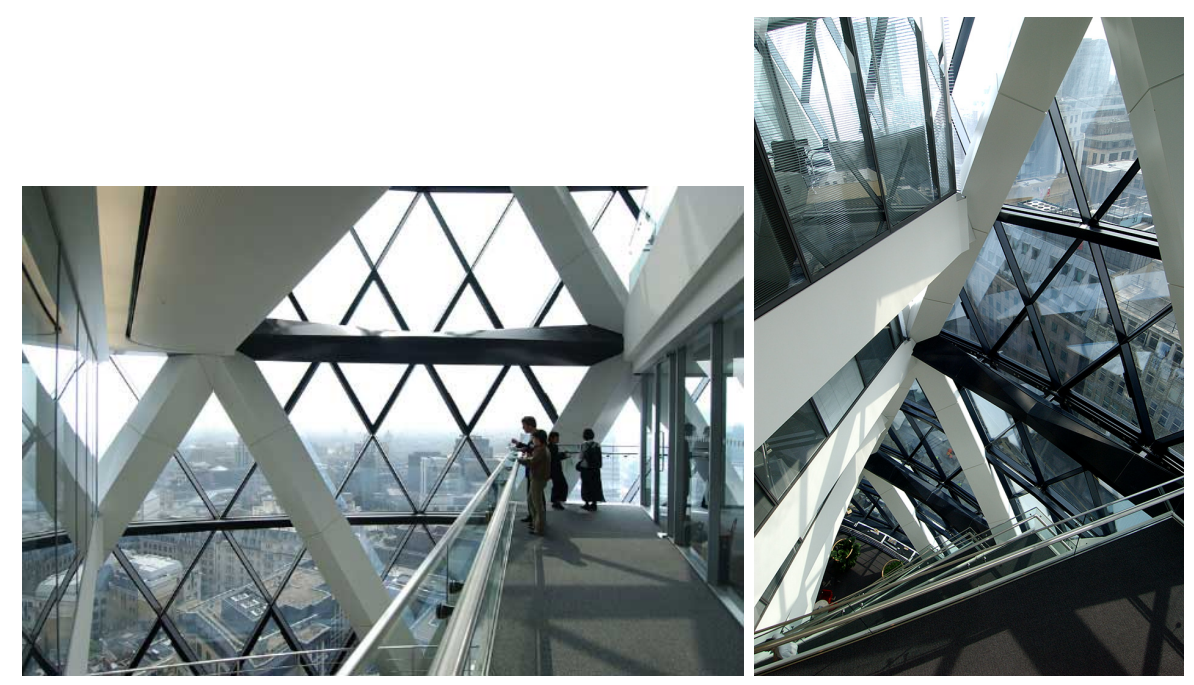

The building's most significant invention remains, however, the floor plate perforations whose locations are geometrically rotated to create 6 separate multi-story atria. Spatially compelling, these vertically aligned diagonally dispersed volumes achieve formal and environmental synthesis as their geometric profiles are optimized for natural ventilation and the exhaust of air. By peeling back the inner IGU skin to the maximum depth of the atrium, building occupants can use the interstitial space it 
creates for circulation and social interaction. At times, however, these atria have highly dynamic thermal environments; such as for example, when partial failure of the façade took place after building tenants reconfigured the envelope's interior architecture to suit programmatic needs, but in so doing significantly altering its performance logic [34].

And notwithstanding this episode, the Swiss Re Tower represents a significant advance in the design of double skin façades. The prismatic design of each of the office panels is carefully synchronized with the structural expression of the diagrids while interconnected atria promote the vertical movement of air, in a manner representationally distinct from the rest of the building using darker bands of colored glass that spiral from the base of the tower to the top of its apex. No more integrated an expression is possible.

Except perhaps, Manitoba Hydro Place; the most recent example of a highly articulate use of architecturally significant spaces for superseding highly inefficient and inadequately performing engineering systems. This project was completed in 2010 in Winnipeg, Canada, by architect Bruce Kuwabara of KPMB Architects (Toronto), energy/climate engineer Thomas Auer of Transsolar (Stuttgart) and executive architects Smith Carter (Winnipeg). This "Integrated Design Consortium" sought maximum reductions in energy use for the new headquarters of the province's Electric and Gas Company [35], and fully aware of the rhetorical power of environmental design, both client and design team were committed to expressing the energy-saving and community building solutions particularly suited to the micro-climate of lower Manitoba.

Two 20-story towers house office spaces for utility employees and two stories of the ground floor are openly accessible by the public, greatly augmenting the urban character of the street. The western and eastern facades are fitted with "biodynamic" double skin façades, so named by the "integrated design" team. The floor-to-floor cavity is approximately $30 \mathrm{~cm}$ deep and acts as a thermal buffer against excessive heating loads. Occupants are encouraged to use operable panels located within the inner IGU skin to help temper the microenvironment of their work area, whereas ventilation panels on the exterior single glazed skin are controlled by a master building automation system (Figure 10).

The particular invention, however, that makes of this project a substantially new prototype for the design of multi-story high performance envelopes, is its use of 9 separate atria for channeling all of the building's fresh air requirements. Having chosen to use closed loop geothermal technology for meeting the majority of the building's heating and cooling requirements, the function of supplying fresh air is reassigned to the architecture. In lieu of typical air-based mechanical air handling units, the south facing building envelope supplies all of the building's fresh air by collecting external air in a series of three vertically stacked atria. These south facing six-story "winter gardens" are the principal conduit for the air that is thereafter distributed to the offices using raised floor displacement ventilation. Given Winnipeg's excessively high heating load, each atrium preheats the outside air by solar heat gain (of which there is much in the winter) and humidifies or dehumidifies as required using open-air drop water fountains. To complete the cycle, a set of six additional atria, three stories each and located on the northern edge of the site, are used to draw exhaust air from the floors expelling this air into an adjacent solar chimney. As such, each atrium is called upon to operate in a complex hybrid-conditioning mode (Figures 11 and 12). 
Figure 10. Manitoba Hydro by Transsolar-Systems Diagram by Brian Christie Design.

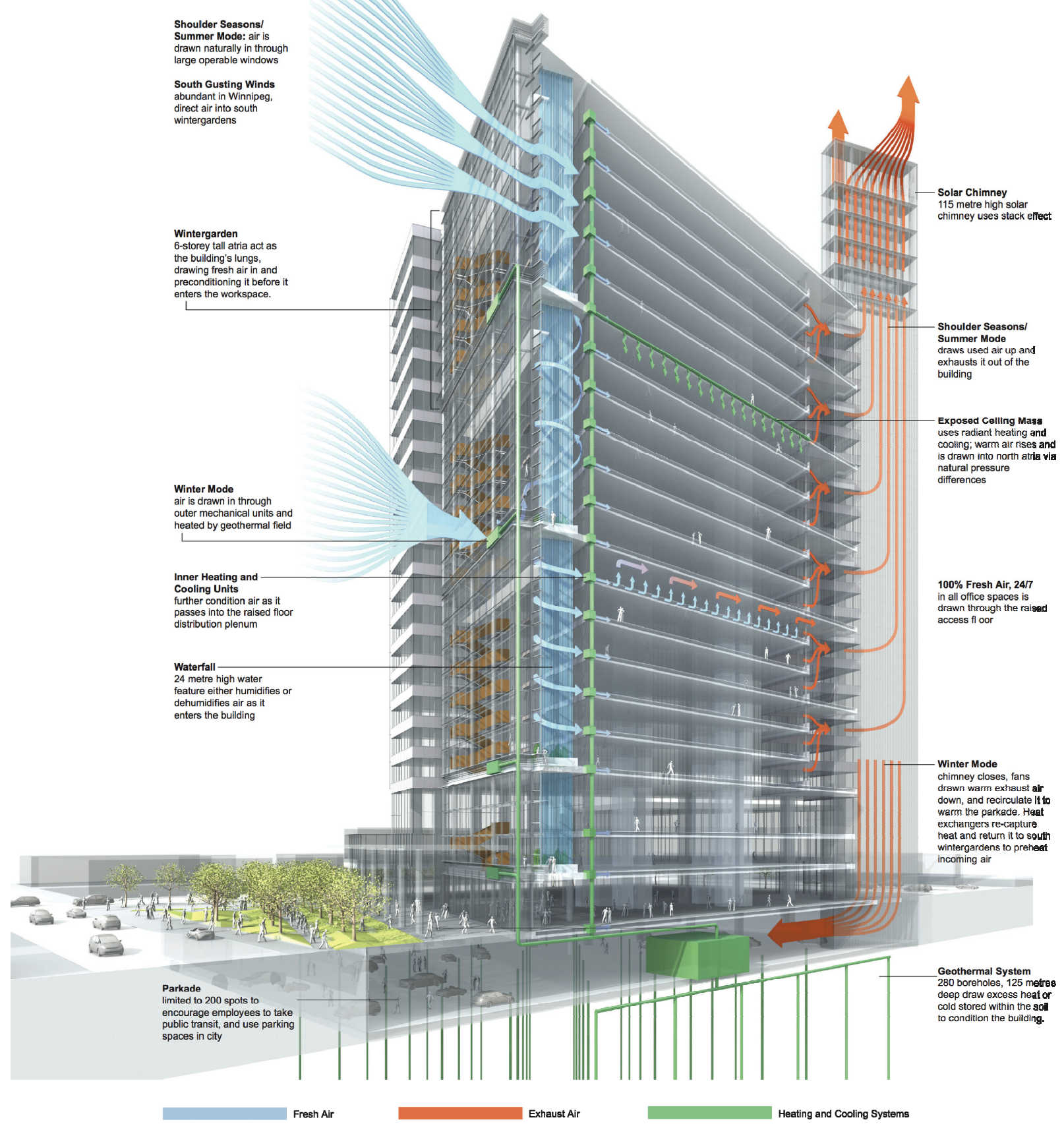

The primary decision to decouple heating and cooling from the supply of fresh air organized most of the building's technological opportunities and solutions. Using efficient water-based heating and cooling radiant systems, raised floors for natural ventilation, and more than 200 geothermal wells, the building reports a $66 \%$ improved energy efficiency over baseline building requirements in the Manitoba energy code. As conceived, executed and operated, the project exemplifies the promise of "spatialised" skins fully integrated in the design of high-performance facades. When optimized to replace less efficient and more highly consuming mechanical equipment, gains are registered financially, architecturally, environmentally, and socially. In the case of Manitoba Hydro Place, each 
atrium performs as a high performance environment while fostering community based functions as a socially active environment. Each of the six atria to the north of the site are used for interoffice communication and informal exchanges between coworkers and colleagues, while the larger winter gardens are used for circulation, conference meetings, and informal social gatherings. In their proportions, details, materials and organization, they offer much architectural delight. The occupants of Manitoba Hydro Place would be far less enriched without daily access to these multi-dimensional communal architectural environments that have been engineered for optimized building systems integration.

Figure 11. Manitoba Hydro Place, Double Skin Façade (Courtesy Terri Boake, University of Waterloo).
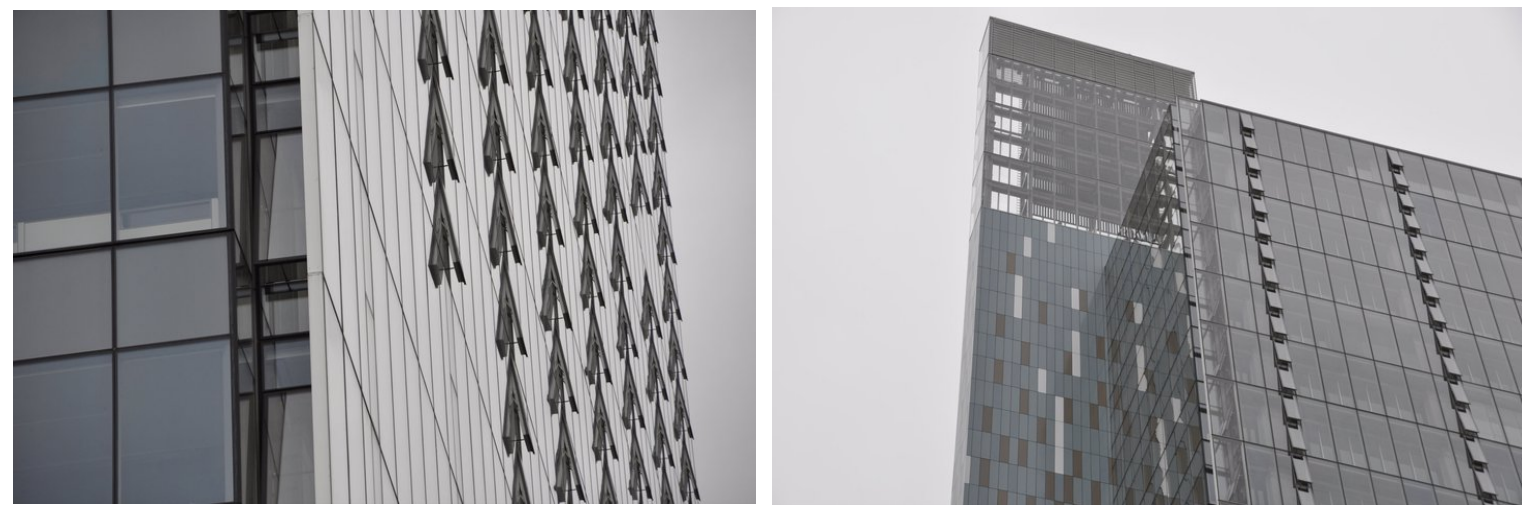

Figure 12. Manitoba Hydro Place, South facing Atrium (Courtesy Terri Boake, University of Waterloo).
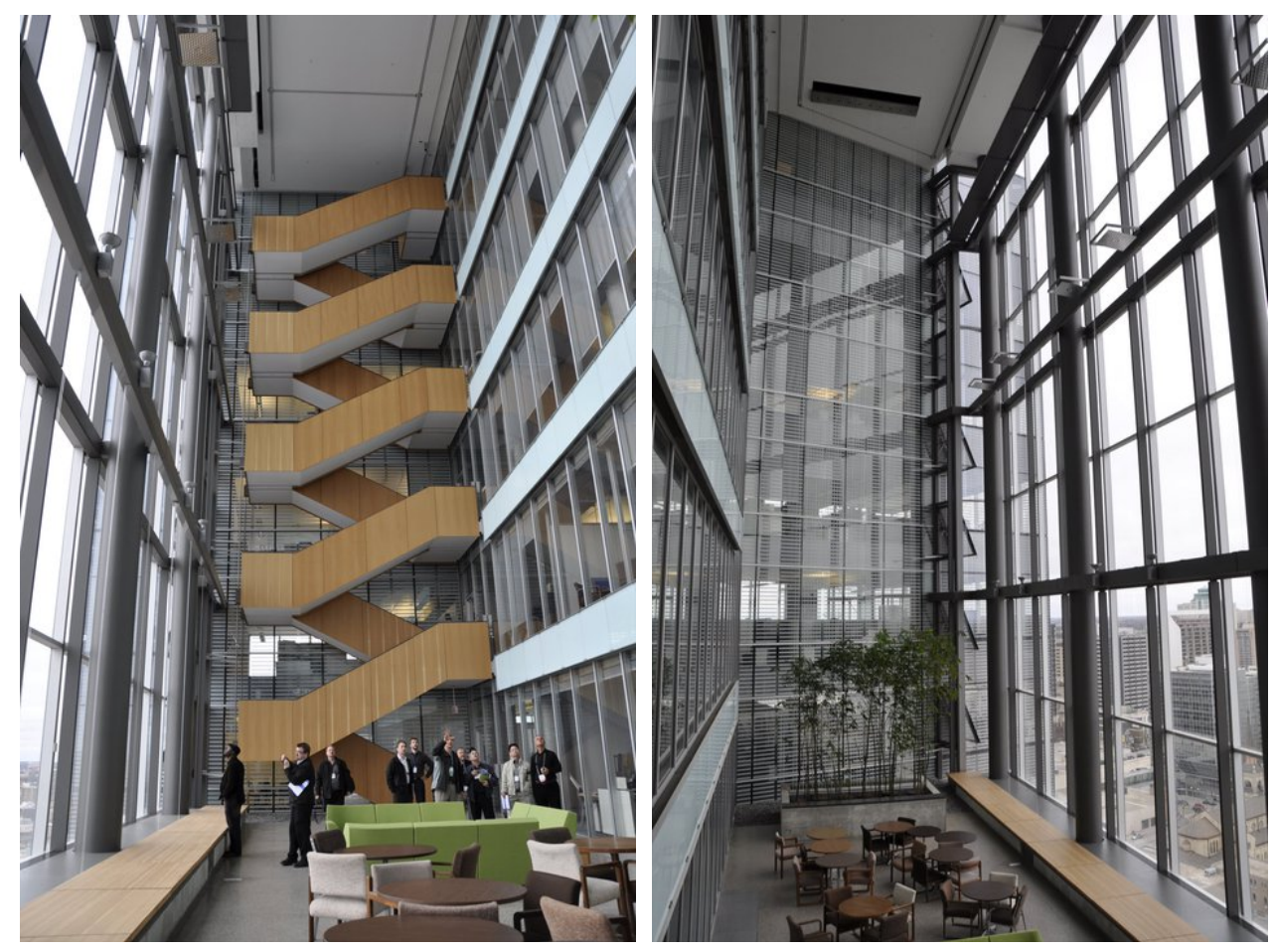


\subsection{Responding to the Surface-Environmental Data Logging}

Three different, albeit linked, envelope based technologies have herein been discussed which openly challenge the reductive paradigm in which facades are conceived as the thinnest of surfaces. No longer governed by an all-consuming desire for dematerialization and maximum transparency, contemporary building façades offer spatially layered alternatives that increase their sectional, material and perceptual depth. Building projections (including louvers and solar shades), double skin facades and large-scale atria reduce the need for energy consuming mechanical systems all the while expanding the architectural value of projects. In each, their "spatially" determined qualities are abundantly evident.

However, the engineering, operation and monitoring of these "spatialized" skins requires a robust electronic interface for logging the full range of dynamic environmental changes which take place in and across their extents. Whether visible to the eye or not, occurring today or tomorrow, these registers render legible and translatable a host of numbers, benchmarks and codes, all of which contribute to the meeting of performance targets. Responsive facades are building envelopes specifically engineered to collect, analyze and respond to performance-based feedback. Digitally and electronically collected, this data encourages instantaneous analysis of the envelope's performance, with the possibility of its modification and redesign, as well as the recommissioning of its affiliated systems. In this sense, most double skin façades are responsive facades when they monitor and record lighting levels, temperature, air velocity, levels of carbon dioxide, and humidity in and across their cavities. The level of intelligence made possible by sensors of all kinds is almost infinite with information collected from a number of different means.

Responsive facades monitor environmental conditions to compare actual performance with early-modeled projections. And when facades operate less than optimally, registering deficiencies is all the more crucial. Once data is collected and measured against a recognized benchmark, the façade can react in one of three ways; it can signal the activation (either on or off) of the data producing element to maintain the system in balance; it can activate (either on or off) an associated component to redress the system's balance; or it can recalibrate the future expected performance of that which is being monitored.

In all instances, what is physically and temporally invisible - the energy contained in the transmission of light, air and air vapor - is given measure and substance through data. In this way, buildings acquire, systematically and over time, levels of artificial intelligence so needed for self-learning and auto-correction [36]. A capacity innate to most members of the biological world, but one still in its formative stages for the built environment, homeostasis is a process that can be used to regulate the survival of all living things. Maintaining a state of balance between internal and external operations is the goal of homeostatic functions as it is of high performance envelopes. When integrated in the context of performance-based envelopes, an overall logic of balance and stability influences the design and operation of this most sensitive of building elements.

A number of signature projects have been conceived and built to rhetorically maximize the true potential of responsive skin technologies, including the early albeit technically unsuccessful all glass sun control façade designed by Jean Nouvel for the Institut du Monde Arabe, in 1987 on the left bank of the City of Paris. The highly articulated jewel-like Masharabiya pattern of all-metal devices 
sandwiched between panels of glass was conceived to open and close in response to changing levels of illumination. As beautiful as the façade was to look it, it was incapable of operating as designed (Figure 13). More recently, a similar solar responsive technique was used to organize the construction and operation of massive operable shading devices for the two 40-story Al-Bahar Towers completed in Abu Dhabi in 2012. In this case, the operative façade stands out board of the building's thermal envelope by two meters and its highly geometrized metal panels are engineered to open and close as required [37]. Designed by the team at Aedas, and supported by the use of responsive actuators, this is the largest responsive solar shading device ever built for directly responding to the path of the sun in a way that maximizes benefits; and the whole, impossible without the collection and analysis of performance based data (Figure 14).

Thus, notwithstanding initial claims made by this paper, for which data is deemed an insufficient metric for measuring the true value of high performance envelopes, equally unacceptable is its absence. Operating in a far more complicated context, evaluating the merit of building envelopes is attendant to the way in which they generate and use highly analytical information as well as the way in which they surpass its very limits. Precisely within this dual condition is found the potential for true invention in the design of high performance envelopes.

Figure 13. Institut du Monde Arabe, Paris France-Jean Nouvel (Courtesy Terri Boake, University of Waterloo).

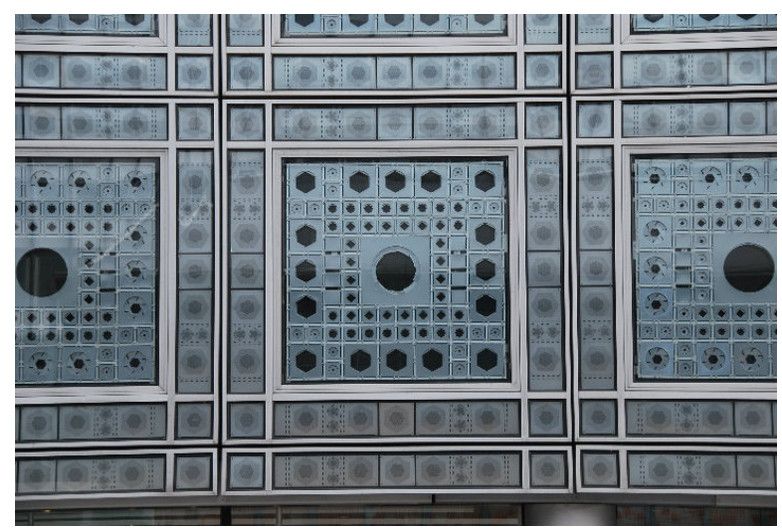

Figure 14. Al Bahar Towers, Abu Dhabi-Aedes (Courtesy Terri Boake, University of Waterloo).

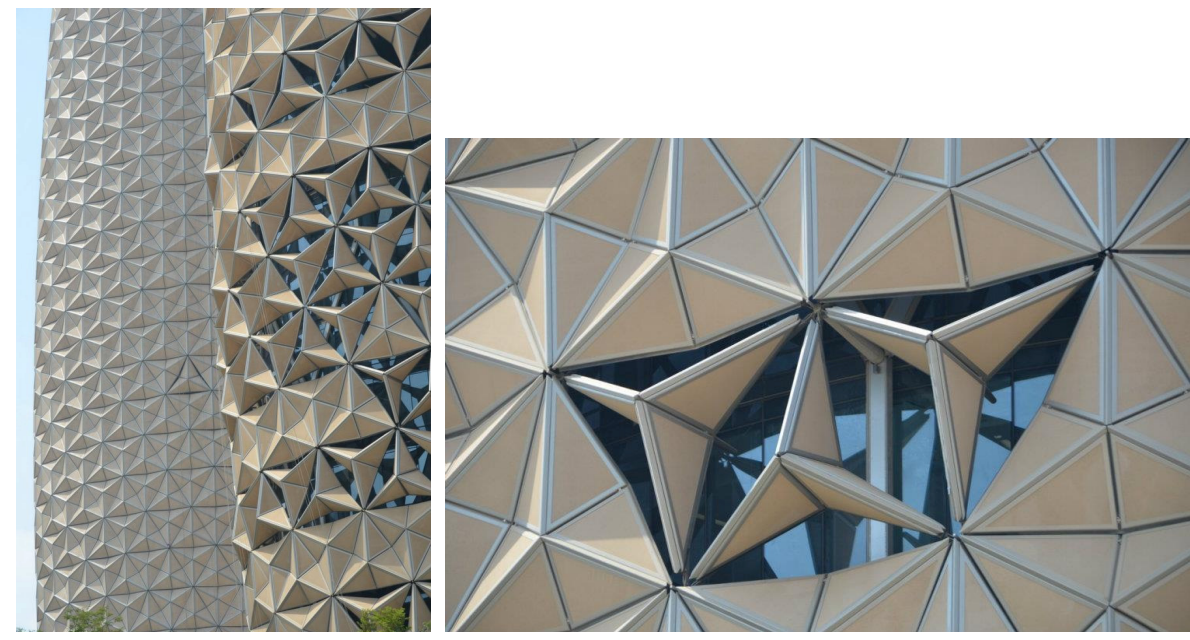




\section{The New Professional-Climate Engineers + Integrated Design Experts}

Delivering high performance façades requires a new range of technical skills and professional aptitudes. In addition to a robust and tested knowledge of building physics, ample competency with a full roster of performance verification technologies is a must. Necessary skills include the ability to conduct detailed building energy audits and to undertake both multi-sector and whole building simulations that measure energy use, daylight, and air circulation. Knowledge of optics and computational fluid dynamics underpins the vast network of digital tools required [38].

And yet, no more fragmented and disjointed a building sector exists than the design, engineering, material sourcing, fabrication, and installation of curtain walls. In fact, when the façade's design and performance is coupled with that of a building's systems, the number of possible complications that arise in coordinating multiparty contracts only escalates exponentially. Required, is an integrated design approach for managing and organizing the various, often-competing voices, that participate in so complicated a process; required is an integrated design professional (Figure 15).

Figure 15. Oldcastle BuildingEnvelope ${ }^{\circledR}$ (Courtesy Brian J. Ganton \& Associates).

\section{Still buying building envelopes this way?}

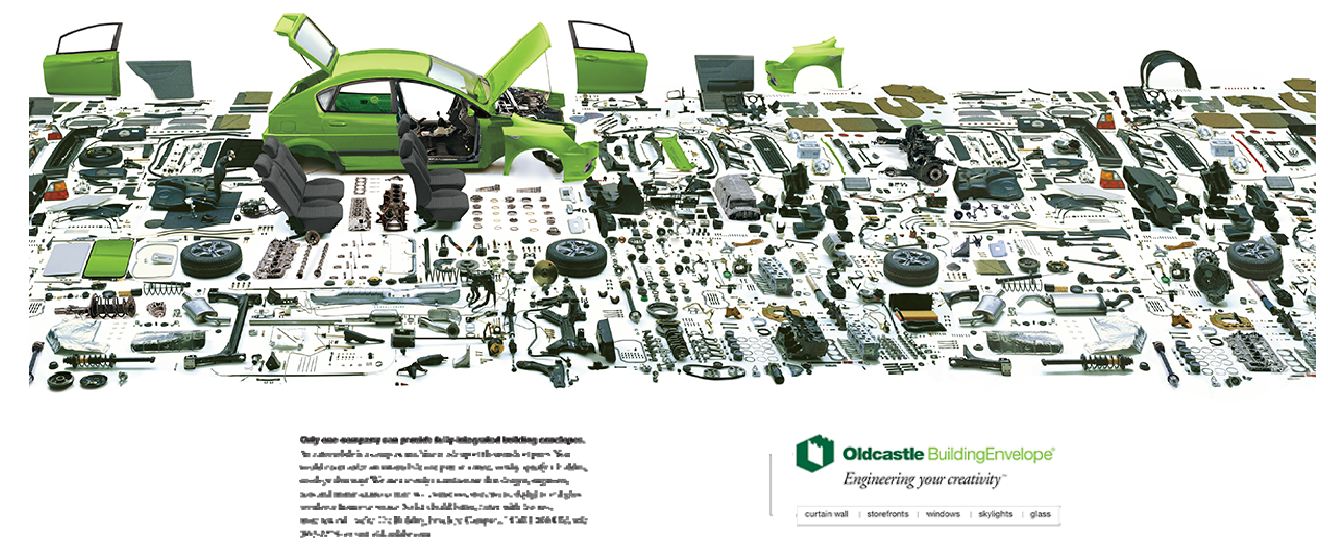

This is the defining characteristic of an emerging group of experts who have made integrated design the center of their professional activities; central to which is an ecological perspective that seeks to fully coordinate building envelope functions with those of its mechanical systems, all the while ensuring accordance with architectural design goals. Climate engineers, environmental design specialists, consultants in life cycle assessment, experts in embodied energy, as well as authorities in alternative fabrication technologies are amongst the cadre of professionals called upon to participate. They mitigate the complexities of this highly disparate building sector and given their range of capacities, often negotiate between opposing performance priorities held by skins, systems and building occupants. Their ultimate goal always being an increase in project value measured across multiple registers including energy savings, augmented human comfort, and excellence in architectural design.

At present, the profile of firms committed to, and experienced in, integrated design is wide ranging. On the one hand, large corporate enterprises such as AECOM market a full roster of design, engineering and construction related services for large scale infrastructural projects in alignment with highly competitive business targets, while smaller studio-based practices, such as façade consultants 
FRONT offer highly articulate design/build expertise for the delivery of sophisticated custom envelope assemblies. Both enterprises share an avowed and advertised commitment to maximizing the advantages of integrated design. And, amongst leading practitioners who operate somewhere in between the fully globalized corporate practice of the former and the craft-based endeavors of the latter are Atelier 10, Atelier One, Werner Sobek Engineers, Buro Happold, and ARUP.

In fact, it was the founder of ARUP Consultants who was the first to clearly articulate and promote the principles, methods and values of this alternative form of practice during the years immediately following WWII. The structural engineer and concrete fabricator Ove Arup was legendary in his commitment to unifying designers, engineers and builders in the process of creating better works of architecture [39,40]. From his early collaborations with the Tecton group in the 1930s, to his signature managerial work on the Sydney Opera House, Arup was the consummate defender of what he termed Total Architecture - the comprehensive integration of all design and construction considerations associated with all parts of the building. Seizing every opportunity to speak in public, to audiences of both architects and engineers, he touted his singular vision to reunite that which modern technology had separated - the values of excellence found in equal measure in design, engineering and construction of significant built works. The company Arup founded is now an international leader in the delivery of integrated design services at all building scales and in more than 75 sectors of the industry. Façade design, materials consultancy, renewable energy, sustainable buildings, and carbon management are amongst the vast list of services they offer. With offices in 36 countries, the makeup of any one firm includes architects, structural engineers, mechanical engineers, electrical engineers, transportation engineers and even materials scientists. ARUP offers a model for collaboration like no other.

A similar commitment to maintaining the highest level of ethics for the building industry guides this new cadre of envelope-based professionals. Beyond their mastery of technical, modeling and digital skills, what sets these practices apart is their clear alignment with an attitude of change. Seeking to transcend the business as usual model, this new cadre of climate engineers and façade consultants strives for higher levels of ecological success at a farmore effective rate then ever before. Personal and corporate stewardship, as well as public education are at the center of their work, and no more representative a group in this regard is that of Transsolar.

In the shadow of Ove Arup, for whom structural engineering was the lens through which his ideas of integration were first articulated, this two decade old practice of climate engineers has repeatedly demonstrated its commitment to an ethical and integrated definition of environmental design. Key participants in the design of the Manitoba Hydro Place and the Linked Hybrid project described above, Transsolar are frequent collaborators with architects Helmut Jahn, Steven Holl and Behnisch Architeckten; architects who recognize the significance of introducing environmental design parameters at the earliest stages of a building's conceptualization. Only in this way can the true merit of its technologies and principles be reconciled.

Central to the core of Transsolar's theoretical position is their promotion of the, at times, unpopular concept of minimizing the use of mechanical systems in buildings. High-performance buildings begin with a concentrated effort in reducing energy load. Achieved in a number of different ways that include expansion of the thermal comfort range, Transsolar invites the power of behavioral modification when asking building occupants to be more tolerant of slightly cooler or warmer interiors, all the while offering them more thermal control over their immediate environments. Regardless of means used 
however, the goal remains the same; augmenting the architectural experience of high performance buildings while securing the energy future of the planet (Figures 16 and 17).

Figure 16. Transsolar Project—Sparkasse Rosenheim: Reprinted with permission from (C) Transsolar.

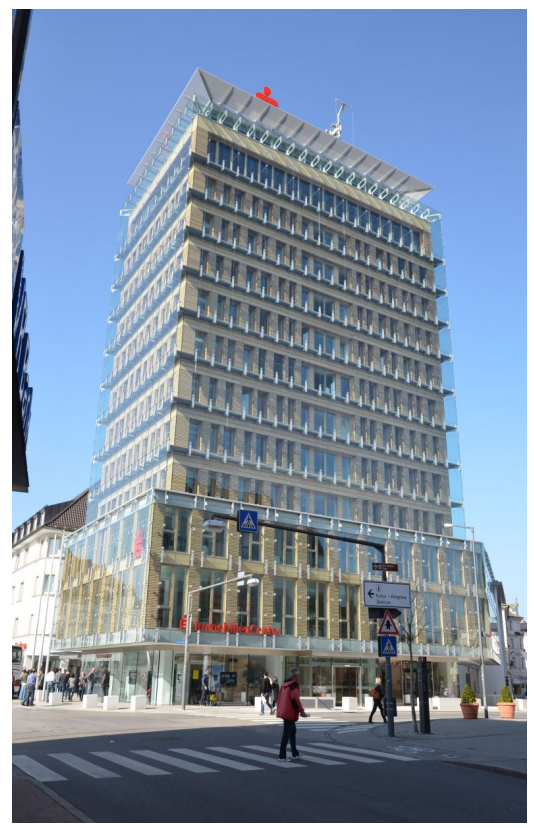

Figure 17. Transsolar Project—Loyola Info Commons: Reprinted with permission from (C) 2008, James Steinkamp, Steinkamp Photography, C Solomon Cordwell Buenzs.

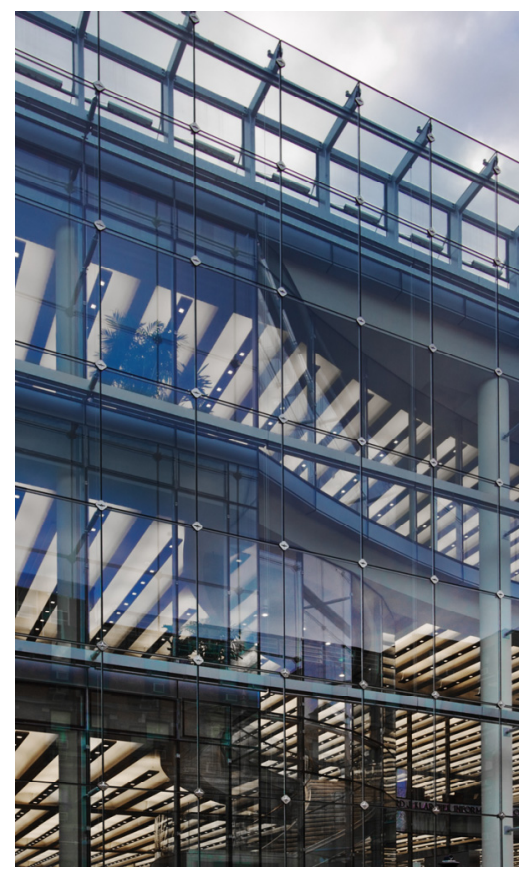

Lofty ambitions indeed, but no less actualized in their daily practice. So committed is Transsolar to the idea that the singular commissioned building remains an insufficient vehicle for communicating their message, and in a manner highly reminiscent of Ove Arup's commitment to education, the founders of Transsolar (Matthias Schuler and Thomas Auer) seek to expand the conversation attendant to high-performance buildings by seizing every available opportunity. In publishing books, organizing 
exhibits and hosting international symposia, this firm creates cultural capital directly associated with the delivery of their inventive ideas and technologies. In 2003, they issued their first monograph titled, Climate Engineering whose very structure was organized according to the four elements-water, air, fire and earth - a most eloquent structure for promoting the importance that fundamental natural principles have in their designs [41]. In 2006, an exhibition catalogue was published to mark their continued cooperation with Behnisch Architekten [42]. In this case, the book was organized according to the themes of temperature, air, sound, light, materials, and human scale. It is of no surprise that their combined brand of sustainable design seeks advanced measures of human value, recognizing the vital role occupants play in the energy consumption of buildings.

The event held most recently to celebrate the first 20 years of the firm's existence marks an entirely new strategy for reaching and expanding its audience. Connect Ideas/Maximize Impact was held in June 2012, in Stuttgart Germany to showcase their core mission and core values. Participants to the conversation included many collaborators mentioned above as well as Bruce Kuwabara of Toronto Canada, Sadhu Johnston of the City of Vancouver, Khaled Awad of Grenea Dubai, and Rahul Mehrotra of Mumbai and Boston. The day's conversations were structured according to the main subjects of Integrated Design and Equity. Seeking actionable protocols for increasing the adoption of both across all sectors of the building industry, participants devised strategies for maximizing the impact of their ideas.

In this and other examples, climate engineers have clearly demonstrated the added value of solving not only the design imperatives of one particular project but of using every project to improve the conditions of all future projects. Building as advocacy, is the particular disposition held by Transsolar, and a number of their colleagues, and it clearly distinguishes this new cadre of professionals that operates well beyond the business as usual model; surely, a vital position to have given the challenges faced by design in the face of a vastly complex environment.

\section{Conclusions}

As argued in the early pages of this paper, contemporary envelopes, when designed using performance based metrics attendant to air, light and heat give rise to an inventive form of practice. While this practice involves the processing of vast amounts of data, it also registers benefits far in excess of said data. Engineering highly responsive facades secures a heightened definition of "performance" when engaging the more speculative dimension of building skins. When novel design ideas are captured and represented across this most liminal of surfaces, the way we think about building envelopes is fundamentally challenged and what emerges is an alternative paradigm for a theory of building. This paper has set out to discuss the various tenets of such a theory.

It acknowledges the extent to which skins are no longer defined by dematerialization, but rather by their propensity for depth. Evident in a number of contemporary design techniques is the way in which they contribute to an increased thickness in the section of the building skin. Whether in the often exaggerated use of cantilevered louvers and solar shading devices, in the proliferation of double skin facades, in the engineering of hybrid condition atria, or in the increased use of building sensors, data collection and responsive design, contemporary building envelopes demonstrate their "spatialization" by a thickening of their dimensions. Acquiring depth in the surface of the envelope has value for 
advanced energy performance, increased human comfort and for the rhetorical role of facades. This aspect of contemporary envelope design is but in its nascent stages and is sure to contribute to further design and engineering inventions.

\section{Acknowledgments}

The author would like to acknowledge all of the photographers and architects who graciously offered their photography for the purposes of illustrating this article.

\section{Conflicts of Interest}

The author declares no conflict of interest.

\section{References}

1. Hegger, M.; Fuchs, M.; Stark, T.; Zeumer, M. Energy Manual-Sustainable Architecture; Birkhauser Edition Detail: Munich, Germany, 2008; pp. 82-109.

2. Powell, K.; Dawson, S. London pride [City Hall]. Archit. J. 2002, 216, 32-33.

3. Sudjic, D. La Casa del Sindaco = London's City Hall. Domus 2002, 852, 40-41.

4. Russell, R.B. Morphosis: San Francisco Federal Office Building. GA Doc. 2002, 70, 92-95.

5. Yukio, F. Morphosis: United States Federal Building. GA Doc. 2007, 96, 56-73.

6. Li, H.; Hideki, H.; Matthias, M.S. On the ground with architect and engineer. $A+U$ 2008, 449, $37-49$.

7. Giebeler, G.; Fisch, R.; Krause, H.; Musso, F.; Petzinka, K.H.; Rudolphi, A. Refurbishment Manual, Maintenance, Conversions, Extensions; Birkhauser Edition Detail: Munich, Germany, 2009.

8. Coyne, M.C. Dollars and (Common) Sense Realizing the Value of Green for Key Users. In Green Building Bottom Line-The Real Cost of Sustainable Building; McGraw Hill: New York, NY, USA, 2009; pp. 199-219.

9. Lovell, J. Building Envelopes: An Integrated Approach; Princeton Architectural Press: New York, NY, USA, 2010.

10. Herzog, T.; Krippner, R.; Lang, W. Façade Construction Manual; Birkhauser Edition Detail: Munich, Germany, 2004.

11. Murray, S. Contemporary Curtain Wall Architecture; Princeton Architectural Press: New York, NY, USA, 2009.

12. Schittich, C. Building Skins; Birkhauser Edition Detail: Munich, Germany, 2006.

13. Dahl, T. Climate and Architecture; Routledge-Taylor \& Francis Group: London, UK, 2010.

14. Stein, R.G. Architecture and Energy Conserving Energy through Rational Design; Anchor Press/Doubleday: New Gloucester, ME, USA, 1977; pp. 108-169.

15. Banham, R. The Architecture of the Well-Tempered Environment; The University of Chicago Press: Chicago, IL, USA, 1984.

16. Kouwenhoven, J.A. Book review: The architecture of the well-tempered environment. Technol. Cult. 1970, 11, 85-93. 
17. Fernandez-Galiano, L. Fire and Memory on Architecture and Energy; MIT Press: Cambridge, MA, USA, 2000.

18. Baird, G. The Architectural Expression of Environmental Control Systems; Spon Press: London, UK, 2001.

19. Banham, R. A home is not a house. Archit. Des. 1969, 39, 45-48.

20. Olgyay, V. Design with Climate: Bioclimatic Approach to Architectural Regionalism; Princeton University Press: Princeton, NJ, USA, 1963.

21. Olgyay, V. Solar Control and Shading Devices; Princeton University Press: Princeton, NJ, USA, 1957.

22. Maloney, J. Designing Kinetics for Architectural Facades; Routledge-Taylor \& Francis Group: Abingdon, UK; New York, NY, USA. 2011.

23. Trubiano, F.; Roudsari, S.M.; Ozkan, A. Building Simulation and Evolutionary Optimization in the Conceptual Design of a High-Performance Office Building. In Proceedings of IBPSA/BS 2013: 13th Conference of International Building Performance Simulation Association, Chambéry, France, 26-28 August 2013.

24. Foster + Partners Home Page. Available online: http://www.fosterandpartners.com/projects/ lycee-albert-camus/ (accessed on 31 July 2013).

25. Trubiano, F. Energy Free Architectural Design: The Case of Passivhaus and Double Skin Facades. In Design and Construction of High Performance Homes; Routledge Press: London, UK, 2012; pp. 37-54.

26. Ford, B. Double-Skin Facades: Improving Performance and Reducing Costs. In Proceedings of Passive and Low Energy Architecture Environmental Sustainability: The Challenge of Awareness in Developing Societies, Beirut, Lebanon, 13-16 November 2005.

27. Balocco, C. Thermal behaviour of interactive mechanically ventilated double glazed façade: Non-dimensional analysis. Energy Build. 2006, 38, 1-7.

28. Poirazis, H. Double Skin Facades. Available online: http://www.ecbcs.org/docs/Annex _ 43_Task34-Double_Skin_Facades_A_Literature_Review.pdf (accessed on 1 August 2013).

29. Gratia, E.; De Herde, A. Are energy consumptions decreased with the addition of a double-skin? Energy Build. 2007, 39, 605-619.

30. Rumford, B. The Complete Works of Count Rumford; American Academy of Arts and Sciences: Boston, MA, USA, 1875.

31. Moe, K. Thermally Active Surfaces in Architecture; Princeton Architectural Press: New York, NY, USA, 2010.

32. Flagge, I. Thomas Herzog, Architecture and Technology; Prestel Books: Munich, Germany, 2002.

33. Norman, F. Catalogue Foster + Partners; Prestel Publishing: Harrisburg, PA, USA, 2008; pp. 310-314.

34. Mehaffy, M.; Salingaros, N. Why Green Architecture Hardly Ever Deserves the Name. Available online: http://www.archdaily.com/396263 (accessed on 31 July 2013).

35. Manitoba Hydro Place Home Page. Available online: http://manitobahydroplace.com/ Integrated-Architecture/ (accessed on 31 July 2013). 
36. Thun, G.; Velikov, K. Responsive Building Envelopes: Characteristics and Evolving Paradigms. In Design and Construction of High Performance Homes; Routledge Press: London, UK, 2012; pp. 75-92.

37. Cilento, K. Al Bahar Towers Responsive Facade/Aedas. Available online: http://www.archdaily.com/270592 (accessed on 31 July 2013).

38. Yi, Y. Building Performance and Computational Simulation. In Design and Construction of High Performance Homes; Routledge Press: London, UK, 2012; pp. 163-177.

39. Tonks, N. Ove Arup: Philosophy of Design; Prestel: London, UK, 2006.

40. Brislin, P. Arup Associates, Unified Design; John Wiley \& Sons: London, UK, 2008.

41. Thierfelder, A. Transsolar-Climate Engineering; Birkhauser Verlag: Basel, Switzerland; Boston: Munich, Germany, 2003.

42. Rappaport, N. Ecology. Design. Synergy: Behnisch Architekten + Transsolar ClimateEngineering; Aedes: Berlin, Germany, 2006.

(C) 2013 by the authors; licensee MDPI, Basel, Switzerland. This article is an open access article distributed under the terms and conditions of the Creative Commons Attribution license (http://creativecommons.org/licenses/by/3.0/). 